Author Accepted Manuscript

Journal:

British Journal of Politics and International Relations

Date of Acceptance:

06.05.2020

Title:

Winner-loser effects in contentious constitutional referenda

- perceptions of procedural fairness and the Brexit referendum

Authors:

Cees van der Eijk (School of Politics and International Relations University of Nottingham)

Jonathan Rose (De Montfort University) 


\title{
Winner-loser effects in contentious constitutional referenda - perceptions of procedural fairness and the Brexit referendum
}

\begin{abstract}
This paper addresses a critical gap in the literature on winner-loser effects that consists of the lack of attention for highly contentious constitutional referenda. It uses unique multi-wave panel data of over 13,000 people that is unrivalled in size and richness. We estimate causal effects of the referendum on rarely studied but crucial public perceptions of the fairness of the way a referendum is conducted. These perceptions pertain to the highly contentious 2016 EU (Brexit) referendum in the UK, which is an ideal-type example of a wider class of referenda for which similar outcomes can be expected. We use differences-in-differences methods and find winner-loser effects of a magnitude far greater than ever observed for general elections. Moreover, we find that these effects not only persist, but even grow over time. The findings have profound implications for the use of such referenda.
\end{abstract}

\section{Introduction}

The seminal contribution by Anderson and his collaborators (see, for example, Anderson et al., 2005; Anderson and Guillory, 1997; Anderson and LoTempio, 2002) sparked a lively field of research on questions of losers' consent and winner-loser effects. Almost without exception this research finds that those who see their preferred side win in elections are more positive than those whose preferred side lose (cf., Anderson et al., 2005; Beaudonnet et al., 2014; Blais and Gélineau, 2007; Delgado, 2016; Howell and Justwan, 2013; Martini and Quaranta, 2019; Singh et al., 2011; Singh et al., 2012; van der Meer and Steenvoorden, 2018). While some disappointment among electoral losers may be expected, the winner-loser gap can pose substantive challenges to political systems.

Such challenges are of at least two different kinds. The first concerns losers' consent. If the group that lost is sufficiently large, and sufficiently disaffected by having lost, the normative basis of legitimacy of political systems that derives from the consent of the governed (see, for example, Locke, 1689; Franck, 1992) may be eroded. The widely subscribed belief that "a democratic political system cannot survive for long without the support of a majority of its citizens" (Miller, 1974: 951) does not specify how large that majority should be, but it should be sizable. Losers' consent can also be a challenge at more mundane levels, particularly when it undermines voluntary compliance with the law, collective decisions and policies (cf., Nagin and Telep, 2017; Scholz and Lubell, 1998). This may be the result of lack of diffuse support (in Easton's terms, 1965). Such diffuse support is particularly important for electoral 'losers'. Simply put, it is easy to support a system that is delivering preferred policies, but it is harder to acquiesce to a system that is not. Diffuse support helps prevent dissatisfaction or disappointment leading to rejection of, and refusal to comply with, policies and policy decisions or, in extremis, rebellion and revolt. Much of the research on losers' consent relates to diffuse support, often operationalised by survey questions about satisfaction with democracy.

The second challenge to political systems that derives from winner-loser gaps relates not to losers' consent for substantive policies, but to their possible lack of confidence in the impartiality of central procedures of democratic governance. Among these are the electoral processes that determine parliamentary and executive power and in the case of referenda, substantive political decisions. The 
focus here is on procedural fairness, which is more specific than the somewhat nebulous but more commonly used focus on satisfaction with democracy. Yet, procedural fairness is of crucial importance because it relates to the democratic basis of the legitimacy of governments. Moreover, elections are supposed to be processes that make inevitable inequalities of political power justifiable (Buchanan, 2002: 710). Thus, if citizens are systematically dissatisfied with elections, and consistently see them as unfair, then there is a very great legitimacy problem indeed. Where strong winner-loser gaps of this nature exist, it reflects not only doubts about legitimacy, but a potentially even more severe problem for a democratic system of the politicisation of legitimacy. Yet this has been rarely studied, and even where studied is often done by reference to data from module 1 of the CSES that is now some 20 years old (see, for example, Singh et al., 2011).

There are important understudied elements within the winner-loser literature. As indicated, one of these involves procedural fairness. Also mostly ignored are winner-loser effects in referenda (for a recent exception that focuses on a district-level referendum, see Marien and Kern, 2018). The winnerloser literature almost always focuses on national-level elections, especially those that decide a country's executive. Yet referenda are not just another context to study winner-loser gaps, they are of major importance because their outcomes will generally have an impact that lasts far longer than a regular electoral cycle. Particularly in the case of contentious referenda that seek to change the constitutional settlement of a country, a referendum can be the most significant electoral competition for a generation, often carrying (ostensibly) irreversible consequences.

From the literature it also remains as yet unresolved what kind of dynamics of attitudes and perceptions are generated by being on the winning or losing side in an election, let alone in the specific context of a referendum. Do winner-loser gaps originate from opposed dynamics (winners becoming more positive and losers becoming less positive), or from asymmetric dynamics (winners becoming more positive, and losers less so)? In light of what has been noted above this is of enormous practical significance. If losers simply gain less than winners, but do not see their positive perceptions decline in absolute terms, then there is little possibility of the more serious consequences discussed above. Conversely, if losers do see their positive perceptions decline noticeably, then more serious concerns could be realised. The lack of systematic evidence here reflects the scarcity of data from consistent panels, as well as the dearth of studies in referendum contexts.

Our study addresses each of these lacunae by using a large and rich panel study (the British Election Study Internet Panel) that contains both traditionally used attitudes and perceptions of fairness in multiple waves of interviews; by leveraging the potential of panel data for differences-in-differences analyses; and by systematically comparing winner-loser effects of the UK's 2016 EU referendum and in the 2017 General Elections in the UK. This article first reviews the winner-loser literature. We then discuss likely differences between referenda and more commonly studied general elections. We discuss our focus on procedural fairness and its measurement. After an overview of the data and our analytical approach we present the results. The conclusion of the paper is that winner-loser effects are much larger for the EU referendum than for a general election, and that they increase over time. Finally, we reflect on the generalisability of our findings, and on their implications for the evaluation of constitutional referenda and further study.

\section{Winner-Loser Effects: Theoretical Background}


The literature consistently shows that those whose preferred side 'won' are more positive towards politics and the political process than those who 'lost'. Nonetheless, the magnitude of these differences varies strongly. Singh et al. (2011), in a cross-sectional study using CSES data from Australia, Canada, Britain and the US covering elections between 1996 and 2005, consistently find a statistically significant winner-loser effect at the national level, but mostly insignificant results at the district level. However, while the effect at the national level was statistically significant, it was of only moderate size for outcome variables such as whether democracy is the best form of government, satisfaction with democracy, or whether elections were conducted fairly (Singh at al., 2011: 703-4). Most often the effect was smaller than that of age, income, or education. Only for direct evaluations of government performance was the 'winner-loser' effect consistently larger than for demographic variables (Singh at al., 2011: 703-4). Similarly, in wide-ranging analyses of election studies from 1972 to 2006 in Britain, Canada, Germany, The Netherlands, New Zealand, Norway, Sweden, and the US, Esaiasson (2011: 106-7) finds mixed results for the size of the winner-loser gap across a range of indicators tapping satisfaction with democracy and system support. Esaiasson sometimes finds statistically and substantively insignificant effects, but sometimes also large effects.

Regardless of the dependent attitudes under study, context appears to be particularly important for the size of the winner-loser effect. Howell and Justwan (2013: 341) demonstrate the importance of margin of victory for electoral winners', but not for losers' satisfaction with democracy. Supporting the winning side in a close election dramatically increases satisfaction with democracy while supporting the winning side in a landslide election makes little difference; yet the magnitude of the margin is irrelevant for electoral losers. Delgado (2016: 81), in a study following the 2011 general election in Spain, also finds a contextually nuanced winner-loser effect upon satisfaction with democracy, in which supporters of losing parties that have recent experience of government are noticeably more satisfied than supporters of parties who do not. Han and Chang (2016: 90) demonstrate an independent effect upon satisfaction with democracy of ideological proximity to the winning parties (see also Delgado, 2016: 80). They also show that financial inequality, measured via the Gini coefficient, has a interaction effect with electoral winner status on satisfaction with democracy whereby the winner-loser effect is smaller in more equal societies. Finally, opportunities for sub-national representation also matter in some situations. Singh et al. (2012), in a study of the 2010 North Rhine-Westphalia state election, and Rose (2014: 84), in a study using data from the UK in 2008, demonstrate not only significant winner-loser effects at the national level, but also positive effects of winning only at the sub-national level (although these findings contrast with those by Anderson and LoTempio, 2002: 346; Singh et al., 2011).

Even more importantly, and crucially significant for gauging potential political consequences of winner-loser effects, are the absolute changes in system support among both winners and losers. Indeed, a large winner-loser gap in system-supportive orientations is possible even when both winners and losers become more positive after the election. This would unlikely lead to significant alienation of the losers and would undoubtedly boost their acceptance of democratic decisions. Indeed, one might hope that free and fair elections will enhance system-supportive orientations among both winners and losers. Assessing absolute rather than relative changes in a wide variety of support indices, Esaiasson (2011: 106-7) finds that increases in positive orientations among both winners and losers in national elections are common, although a gap between winners and losers usually remains. Similarly, and again reinforcing the supremacy of national-level winning, Singh et al. (2012: 206) observe "being in government boosts satisfaction, while going into opposition does not foster dissatisfaction." Van der Meer and Steenvoorden (2018), using a panel study of the 2012 Dutch Lower House elections find positive (but small) effects of an election upon both political losers and nonvoters; while again the gains are larger for supporters of the electoral winners. While there may be 
some conditionality within these results from the specific cases analysed and of how individuals experienced patterns of (repeated or alternating) winning and losing over electoral cycles, there is rough consistency across cases that losers' evaluations of the system and its procedures do not tend to decline much if at all.

While the literature tends to find that losers generally do not see their system-supportive orientations decline much, if at all, there is little research to suggest whether this finding could be expected to apply to all political competitions. As already noted, analyses of winner-loser effects are predominantly based on elections, which are routine and repeat periodically. Much less research has been done on the winner-loser gap in referenda (for a recent exception studying short-term effects in a local referendum in Belgium, see Marien and Kern, 2018). Yet it is a priori unlikely that the general form of the effect following ordinary elections -differential increases in system-supportive orientations- will carry over to referenda. For several reasons referenda are more likely to produce outsized winner-loser effects, and moreover to show a decline in positive perceptions among losers.

Firstly, a significant proportion of voters have strong electoral preferences for more than one party (van der Eijk and Franklin, 2009: 52). Thus, in ordinary elections it is possible that people not ordinarily considered 'winners' might nonetheless see their second most preferred party win. This may explain the observed effect of ideological proximity on post-election satisfaction with democracy (Delgado, 2016; Han and Chang, 2016; see also Leiter et al., 2019). Moreover, in systems that habitually produce coalitions, 'winning' has a broader meaning that encompasses being included in a coalition (van der Meer and Steenvoorden, 2018). In referenda, however, the likelihood that losers regard the option they did not vote for as an acceptable second-best is much more remote. Indeed, the dichotomous choice presented by many referenda seems more likely to lead to higher levels of polarization. Losers are therefore likely to decline in their system-supportive orientations following referenda. Moreover, while the magnitude of winner-loser effects in regular electoral contexts may be limited because winners in one election are often losers in another, such countervailing and mitigating influences are usually absent in the case national referenda.

Secondly, as noted earlier, losers who have recent experiences of seeing their party in government are generally more satisfied than those who do not, indicating the existence of a carry-over effect in system-supportive orientations (Delgado, 2016: 81). Referenda, by contrast, are usually one-shot competitions. Thus, it is unlikely that there will be any compensatory effects from previous electoral victories. Moreover, past research on the moderating role on the winner loser effect of recent experience with governing implies that an expectation of seeing one's most preferred party in government at some future point in time is also a moderating factor. However, referenda are not ordinarily re-run, and issues decided by referenda may be taken as politically 'settled' for a significant period. It is therefore plausible that losers in referenda may feel their loss to be perpetual, which again would increase winner-loser effects.

In sum, we may reasonably expect referenda to have an outsized winner-loser effect, relative to much more commonly studied general elections. Nonetheless, it is still uncertain exactly how large the effect will be in the context of a highly salient national referendum and whether losers will get more negative absolutely or simply fail to gain in positive perceptions.

\section{Winner-Loser Effects: the Dependent Variable(s)}

The winner-loser literature frequently takes satisfaction with democracy as the dependent variable (cf., Blais and Gélineau, 2007; Delgado, 2016; Han and Chang, 2016; Martini and Quaranta, 2019). 
Satisfaction with democracy is an important evaluation of a democratic political system, and is generally interpreted as an indicator of diffuse support for the existing political regime. Nonetheless, the literature is rife with discussions about what 'satisfaction with democracy' exactly means, and about the extent to which it represents Easton's (1965) concept of diffuse support (see, for example, Anderson and Guillory, 1997: 70; Ezrow and Xezonakis, 2016; Linde and Ekman, 2003). Moreover, satisfaction with democracy is inherently less specific than evaluations that directly relate to a single electoral competition. Precisely because of this, satisfaction with democracy is less helpful for considering whether people will regard specific collective decisions as legitimate. For that purpose, evaluations of procedural fairness of electoral competitions are more relevant.

Perceptions of procedural fairness are of crucial importance. A range of research has shown that people are more likely to accept decisions that go against their individual interests or preferences if they believe those decisions were obtained in a procedurally fair manner (cf. Tyler 1988; Tyler 2003). Much of this work has taken place in the context of policing, but the same effect also appears in relation to rulings of the United States Supreme Court which involve broader public policy issues (Tyler and Rasinski 1991). Procedural fairness is especially important with respect to general public policy making. An experimental study of acceptance of systemic tax law changes demonstrates that support was higher for decisions made using a fair procedure irrespective of how beneficial or detrimental the decision was individually, even though acceptance of ad hoc individual tax decisions did not show a fairness effect (Niesiobędzka and Kołodziej 2017). In 27 small scale studies ( $n=57-312$ ) of decision acceptance of changes to school-level educational regulations, Esaiasson et al. (2019) show a significant effect of perceived procedural fairness on decision acceptance, alongside a key role of outcome favourability. Nonetheless, because neither Niesiobędzka and Kołodziej (2017) nor Esaiasson et al. (2019) focus on national level electoral competitions, it is difficult to derive clear expectations from their research for the role of fairness perceptions in referenda and general elections.

Regardless of the effect of procedural fairness on outcome acceptance, perceptions of procedural fairness have frequently been shown to lead to greater compliance with the law (for a review, see Nagin and Telep, 2017), and to boost perceived legitimacy of collective decisions (Martin et al., 2020), which in turn drives support, compliance and acquiescence (Sunshine and Tyler, 2003). At the same time, perceptions of electoral fairness are also importantly associated with turnout, which is higher among citizens who believe that the election is likely to be fair (Birch, 2010). Enhanced engagement is again plausibly related to greater perceptions of the legitimacy of systems, as well as being a good in its own right. More generally, procedural fairness itself is a normative good, and its presence is always better than its absence.

Perceptions of procedural fairness are therefore important for tracking the extent to which individuals believe they experience a fair system, but are arguably of greater importance politically, because individuals act based on their perceptions rather than the objective facts on the ground. Moreover, because perceptions of the fairness of elections seem to have an important role in outcome acceptance, over and above the important role of decision favourability, they are likely to be a particularly important concern in the context of contentious political competitions. Therefore, we focus our research upon perceptions of procedural fairness.

\section{Data}


We use data from the British Election Study Internet Panel (BESIP), which is the first large scale British survey since the late 1990s that contains questions about the fairness of the electoral process. ${ }^{1}$ Wave 1 of BESIP was fielded in February/March 2014; we focus mainly on waves 7, 9, 10 and 11, which cover the period of April 2016 to early May 2017. Fieldwork for Wave $7(n=30,895)$ was between 14 April and 4 May 2016 (shortly before the EU referendum of 23 June); for wave $9(n=30,036)$ between 24 June and 4 July 2016 (immediately after the EU referendum). Wave $10(n=30,319)$ was fielded between 24 November and 12 December 2016 during a relatively quiet period after Theresa May assumed the position of Prime Minister in July, and while specifics of her Brexit policy still had to take shape. Wave 11 ( $n=31,014)$ was fielded between 24 April and 3 May 2017, shortly after the government notified the European Union formally of its intention to leave (29 March), and also shortly after the early General Election of 2017 was called (on 18 April 2017), but before the hot phase of the campaign for this election. Occasionally we use data from other waves, at which times we will briefly introduce the context in which those waves took place.

The number of respondents that were surveyed in all these four waves is smaller than indicated above (because of attrition and replenishment of the panel), but still amounts to a respectable 13,115 . To avoid comparison problems arising from compositional differences, we conducted all analyses reported below on this subset of 13,115 respondents. To approximate the characteristics of the British population, and in particular because the BESIP deliberately oversampled Scottish and Welsh respondents, we conducted our analyses on weighted data. This translates into a weighted $n$ of 9,373. For details of sampling and of weights we refer to the BESIP documentation. ${ }^{2}$

As indicated earlier, our focus is on the magnitude of the winner-loser effect of the EU Referendum outcome on perceptions of the fairness of the referendum. Questions about this were included in the questionnaires of BESIP waves 7, 9, 10 and 11, as follows:

\section{How fairly do you expect the EU referendum to be conducted? (wave7) and \\ How fairly do you think the EU referendum was conducted? (wave9, wave10, wave11).}

Each of these questions could be answered via a 5-point rating scale with 1 labelled as 'conducted fairly' and 5 as 'conducted unfairly'. Respondents could also indicate 'don't know'.

1 The BES Internet Panel (Fieldhouse et al., 2018) is available for secondary analysis at https://www.britishelectionstudy.com/data-objects/panel-study-data/. The most recent previous study containing questions about the fairness of the electoral process was the 1997 British Election Study (CREST 1999), which included the question: "In some countries, people believe their elections are conducted fairly. In other countries, people believe their elections are conducted unfairly. Thinking of the last general election in Britain, where would you place it on this scale of one to five where ONE means that the last election was conducted fairly and FIVE means that the last election was conducted unfairly?"

2 See the 'Technical Document' (https://www.britishelectionstudy.com/wp- content/uploads/2014/05/ BES Wave1 tech.pdf) and pages 4-5 of the Combined Waves 1-14 Internet Panel Codebook. The Supplementary Materials provide the complete syntax of our analyses, including the specification of the weight variables that were used. In all our analyses, weighted data give rise to very similar results as unweighted data (despite the oversampling of Scotland and Wales in the unweighted data). Moreover, for all our analyses the results are very much the same had we used all cases from waves 7, 9, 10 and 11 (i.e., if we had also used respondents who, because of attrition or top-up, took part in only one or some of four waves). Thus, neither weighting, nor restricting our analyses to the specific group of 13,115 respondents participating in all four waves has any substantive effect on our findings. 
Although the questions are formulated differently, prospectively in wave 7 and retrospectively in waves 9,10 and 11, they are obviously equivalent in their substantive meaning, and therefore we can compare the responses over-time.

Equivalent questions relating to the General Election of 2017 were included in BESIP Wave 11 (prospective) and Wave 13 (retrospective), and, although these are not at the heart of the study we report here, we use these questions to put the estimates of the winner-loser effect on the fairness of the EU Referendum into a broader perspective. We introduce additional variables, used as controls or to distinguish groups, at the time that they are used. These variables and their coding are reported in Section 1 of the online Supplementary Materials.

\section{Analytical approach}

As indicated earlier we are not primarily interested in the distribution of responses to the questions about the fairness of the EU Referendum, or in explaining the variance of these responses. Instead, we are interested in how these answers changed from before to after the referendum as a consequence of the referendum outcome. Such changes reflect winner-loser effects much more directly than cross-sectional analyses which focus on response differences between winners and losers. The panel character of our data allows us to observe individual-level changes in responses to the referendum fairness question and assess to what extent these changes are attributable to one's status as winner or loser in the referendum. The procedure we use for this is differences-in-differences (d-i-d) analysis.

D-i-d estimation is a well-established procedure that is often used in empirical studies in economics, policy evaluation, education and health research. It compares the difference in responses between groups of cases that are 'treated' differently by an event. It compares these differences between the groups before and after the event, which is in our case the EU referendum. The two groups of relevance in our analyses are 'referendum winners' (those who voted to leave the EU) and 'referendum losers' (those who voted to remain in the EU). Although none of the respondents were winners or losers before the referendum, the panel structure of the data allows us to identify the eventual winners and eventual losers in pre-referendum waves.

The $d-i-d$ approach helps to address two endemic problems when pursuing the estimation of causal effects in nonexperimental data: selection bias and the confounding effect of other (exogenous) factors than the event in question (see, e.g., Angrist and Pischke, 2009; Imbens and Rubin, 2015; Imbens and Wooldridge, 2009; and Shadish et al., 2002). Most assumptions of a d-i-d design are met by the panel character of the data, by our use of a fixed group of respondents (only those who participated in all four waves of interest), and by the unequivocal time sequence of observations and the referendum. Yet, three aspects of our use of $d-i-d$ are not trivial and require some explanation.

The first, somewhat uncommon element in our application of $d-i-d$ is that it deviates from its classic form in which only one of the two groups is exposed to a treatment, while nothing changes for the other group (the control group). This definition of treatment is not plausible in our case. The outcome of the referendum does not only designate the 'leave' voters as winners, but simultaneously designates the 'remain' voters as losers. In short, both groups are 'treated', but in opposite ways, and there is no untreated 'control group'. Although most discussions of $d$-i- $d$ focus on the comparison of a treated and an untreated group, the d-i-d design is actually quite flexible and can be applied to a wider set of conditions than this simple classic case (cf., de Chaisemartin et al., 2018; Fricke, 2017; Wing et al., 2018). In our case we apply a form of $d$-i-d analysis that utilises a 'reversed treatment 
control group' (as used by, e.g., Hackman et al., 1978; see also Shadish et al., 2002: 147-148, who emphasise its strengthening of construct validity).

The second aspect that warrants some discussion relates to a central assumption of $d$-i-d analyses, known as the parallel trend assumption. This holds that, had the referendum not taken place, the groups compared would exhibit the same change over time. The plausibility of this assumption can only be assessed if the referendum fairness question would have been asked at multiple times before the referendum. Unfortunately, that was not the case. However, we can use another variable as a functional proxy: satisfaction with democracy. Although it is more diffuse in character than the referendum fairness question, it also taps into evaluations of political processes in the country. ${ }^{3}$ This question has been asked repeatedly before the referendum, thus allowing a 'placebo test' of the parallel trend assumption (reported in Section 2 of the online Supplementary Materials). The results of this test provide compelling support for the parallel trend assumption, on which the validity of $d$-id effects rests.

The third aspect of our estimation of $d$-i-d effects that needs to be explicated concerns covariates. We use covariates to control for factors that may affect the individual (i.e. person level) response to the treatment, and which may differ systematically between the two groups. Controlling for these thus reduces the risk of incorrectly attributing response changes to the differential treatment of the groups. We use only variables as covariates that have been observed before the referendum, and that therefore cannot have been influenced by the winner-loser distinction. In the analyses to be reported later we use as covariates gender, age, education, ethnicity, nationality and social grade (details about the measurement of these covariates are provided in Section 1 of the online Supplementary Materials).

We estimate d-i-d effects with the Stata module diff (Villa 2016), using the fixed set of 13,115 respondents that participated in all relevant waves of BESIP (waves 7, 9, 10 and 11), with a weighted $\mathrm{n}$ of 9,373 (see also footnote 2). The dependent variable (referendum fairness) is an ordered categorical variable (ranging from 1 to 5). One could question the appropriateness of the linear regression procedures that underlie $d-i-d$ analyses, and whether other procedures (e.g., various forms of logit or probit analysis) would be preferable. Although this would be possible in principle, the disadvantage is that, as Lechner (2011: 198) explains, such specifications usually lead to inconsistent differences-in-differences estimators. Moreover, as Hellevik (2009) convincingly demonstrates, the advantage of such nonlinear specifications over OLS is small if the dependent variable is not very skewed. For these reasons, we use $d-i-d$ models that are based on straightforward linear regression procedures.

\section{Results}

As stated earlier, we focus on winner-loser effects in responses to referendum fairness questions. Table 1 presents the response distribution of this question for each of the four waves.

\footnotetext{
${ }^{3}$ Moreover, in the waves in which both the referendum fairness question and the satisfaction with democracy question were included, we find that they are significantly correlated (Loevinger $\mathrm{H}$ coefficient is 0.32 ; see Van Schuur, 2011)
} 
Table 1 Distribution of responses to referendum fairness question

\begin{tabular}{|c|c|c|c|c|c|}
\hline & & $\begin{array}{l}\text { Wave } 7 \\
\text { pre- } \\
\text { referendum }\end{array}$ & $\begin{array}{l}\text { Wave } 9 \\
\text { immediate post- } \\
\text { referendum }\end{array}$ & $\begin{array}{l}\text { Wave } 10 \\
5 \text { months post } \\
\text { referendum }\end{array}$ & $\begin{array}{l}\text { Wave } 11 \\
10 \text { months post } \\
\text { referendum }\end{array}$ \\
\hline 1 (fair) & \multirow{7}{*}{ 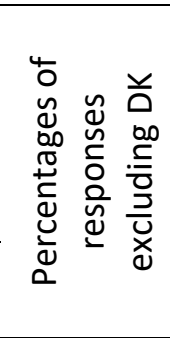 } & 26.3 & 30.4 & 33.2 & 33.5 \\
\hline 2 & & 18.0 & 13.8 & 12.3 & 12.3 \\
\hline 3 & & 24.8 & 23.3 & 20.2 & 19.6 \\
\hline 4 & & 16.5 & 14.5 & 16.7 & 16.4 \\
\hline 5 (unfair) & & 14.4 & 18.0 & 17.7 & 18.2 \\
\hline Total fair $(1+2)$ & & 44.4 & 44.2 & 45.5 & 45.8 \\
\hline Total unfair $(4+5)$ & & 30.9 & 32.5 & 34.4 & 34.6 \\
\hline $\begin{array}{l}\text { \% DK in weighted } \\
\text { sample }\end{array}$ & & 20.1 & 11.2 & 13.0 & 12.8 \\
\hline $\begin{array}{l}\text { Weighted N } \\
\text { (rounded) }\end{array}$ & & 9,373 & 9,373 & 9,373 & 9,373 \\
\hline Unweighted N & & 13,115 & 13,115 & 13,115 & 13,115 \\
\hline
\end{tabular}

Source: BESIP; based on weighted data; only respondents who participated in all four waves

Table 1 shows some interesting changes which occur against the backdrop of considerable aggregate stability. The proportion of people who perceived the referendum as having been conducted (at least somewhat) fairly (categories 1 and 2 combined, see row labelled 'total fair') remains stable over time at around $45 \%$, with a slight increase in the percentage in category 1 (at the expense of category 2 ). On the other pole (row labelled 'total unfair', comprising categories 4 and 5) we observe a slight increase from about $31 \%$ to about $35 \%$, most of this increase is to category $5 .{ }^{4}$ The middle response category (3) becomes gradually smaller. The magnitude of these changes is limited, but jointly they result in a gradual increase in polarisation of the responses. In addition to these limited shifts in the distributions of valid responses we observe also a strong drop in the percentage of don't know responses, from about $20 \%$ to about $13 \%$.

The limited changes in these overall response distributions mask, however, a tremendous degree of churn below the surface, which is strongly related to whether respondents find themselves after the referendum on the winning or losing side. It is these changes that we now concentrate on.

Table 2 presents the results of a $d$-i-d analysis on the responses to the referendum fairness question asked shortly before and immediately after the referendum (BESIP waves 7 and 9). As the same individuals are observed at the two moments in time, we estimated clustered standard errors. ${ }^{5}$

\footnotetext{
${ }^{4}$ Although it does not concern the main focus of our study, the percentage of responses in the 'total unfair' row (31-35\%) is in our view disconcertingly high for an established democratic system.

${ }^{5}$ In all the $d-i-d$ analyses reported means and standard errors are estimated by linear regressions that lie at the basis of the diff procedure. These regressions are performed with pairwise deletion of data; this makes it impossible to report the numbers of cases involved in an analysis in a single number. Instead we report $\mathrm{N}$ as a range of the numbers of cases included in the pairwise covariances between the respective variables. Missing data (leading to cases not being included in the calculation of the covariances between variables) are generated by respondents who did not vote in the referendum, and by don't knows on the variables involved in the analysis.
} 
Table 2 Differences-in-differences analysis of responses to referendum fairness question

\begin{tabular}{|c|c|c|c|c|}
\hline & $\begin{array}{l}\text { Estimated mean on } \\
\text { referendum } \\
\text { fairness question } \\
\text { ( } 1=\text { fair; } 5=\text { =unfair) }\end{array}$ & $\begin{array}{l}\text { Standard } \\
\text { error }\end{array}$ & $|t|$ & $\mathrm{p}$ \\
\hline \multicolumn{5}{|l|}{ Before referendum (wave 7) } \\
\hline Remain voters & 2.717 & & & \\
\hline Leave voters & 3.540 & & & \\
\hline Difference & 0.823 & 0.047 & 17.57 & $<.0005$ \\
\hline \multicolumn{5}{|l|}{ After referendum (wave 9) } \\
\hline Remain voters & 3.635 & & & \\
\hline Leave voters & 2.784 & & & \\
\hline Difference & -0.850 & 0.050 & 16.95 & $<.0005$ \\
\hline D-i-d (winner-loser) effect & -1.673 & 0.058 & 29.09 & $<.0005$ \\
\hline
\end{tabular}

Note: groups defined on referendum vote (leave vs. remain voters); data from BESIP; covariates specified in text; clustered standard errors; only respondents who participated in all four waves $(7,9,10,11)$; weighted data (weighted $N=7593-7984-$ see footnote 5)

As Table 2 shows, the eventual leave voters were (before the referendum) considerably less convinced about the fairness of the referendum than the eventual remain voters: their respective means on the 5 -point scale are 3.54 and 2.72, resulting in a difference of means of 0.82 . After the referendum the positions of the two groups reversed, and the magnitude of the change makes it an almost perfect swap between the positions of the two groups. This pattern of changes contradicts suggestions that a winner-loser difference might originate from different rates of change in the same direction (Esaiasson, 2011; Singh et al., 2012; Van der Meer and Steenvoorden, 2018). We find this pattern in all our $\mathrm{d}$-i-d analyses. The post-referendum averages are 2.78 for leave voters, and 3.64 for remainers, which gives a difference of their means of -0.85 (in the other direction as before the referendum, hence the minus sign). The combination of the two differences of group means yields the differencesin-differences estimate, which is -1.67 . The estimated $d$-i-d effect is a proper winner-loser effect that reflects how strongly perceptions of referendum fairness have changed because of having been on the winning or on the losing side of the referendum. This $d$-i-d effect is significant but given the large $N$ (9373) that is unsurprising. Of greater interest is the large absolute magnitude of the d-i-d effect, 1.673 on a dependent variable with a range of 5 .

The most obvious interpretation of the origin of the effect reported in Table 2 is the respondent's status as winner or loser in the referendum. One could wonder, however, whether the findings could be interpreted in other ways. Two potentially rivalling interpretations come to mind. One is that the effect was generated by other, contemporaneous stimuli and events. A second potential problem is that the effect may be partly endogenous if expectations about the outcome would already have been factored in pre-referendum responses to the fairness question. Both potential problems can be assessed using other variables from the pre-referendum questionnaire.

The interpretation that the $\mathrm{d}-\mathrm{i}-\mathrm{d}$ effect is generated by being on the winning or on the losing side of the outcome implies that respondents were 'treated' with a political outcome that they desired (leave voters), or that they did not desire (the 'reversed' treatment for remain voters). The logic of this argument has as an observable implication that the magnitude of the winner-loser effect should correlate with how strongly respondents desired or abhorred the outcome. This can be tested empirically, using the (wave 7, pre-referendum) question: "How will you feel if Britain votes to leave the EU?" with response options 'Very unhappy' (1); 'Somewhat unhappy (2); 'A little unhappy' (3); 
'Indifferent' (4); 'A little happy' (5); 'Somewhat happy' (6); and 'Very happy' (7). ${ }^{6}$ Combining categories of equal strength of feeling on both sides of the divide ( 1 and $7 ; 2$ and $6 ; 3$ and 5 ) leads to 4 categories, ranging from very strong feelings about the outcome to indifference. We conducted $d-i-d$ analyses for each of these groups and report the estimated winner-loser effect in Table 3 (more detailed results are reported in Section 3 of the online Supplementary Materials).

Table 3 Magnitude of winner-loser effect on perceived referendum fairness for different strengths of preference for outcomes

\begin{tabular}{lcccc}
\hline $\begin{array}{l}\text { How will you feel if Britain } \\
\text { votes to leave the EU? }\end{array}$ & $\begin{array}{c}\text { D-i-d (winner-loser) } \\
\text { effect }\end{array}$ & $\begin{array}{c}\text { Standard } \\
\text { error }\end{array}$ & P & N (weighted) \\
\hline Very (un)happy & -2.587 & .156 & $<.0005$ & $841-869$ \\
Somewhat (un)happy & -1.715 & .217 & $<.0005$ & $445-450$ \\
A little (un)happy & -0.995 & .290 & $<.001$ & $342-351$ \\
Indifferent & -0.503 & .288 & $<.083$ & $155-158$ \\
\hline
\end{tabular}

Note: groups defined on referendum vote (leave vs. remain voters); data from BESIP; covariates specified in text; clustered standard errors; only respondents who participated in all four waves $(7,9,10,11)$; weighted data (see footnote 5 for explanation of $n$ )

Table 3 shows that the stronger respondents' preferences about the outcome of the referendum, the larger the winner-loser effect is. This supports our interpretation of the $d$-i-d effects in winnerloser terms. At the same time it reduces the plausibility of the effect having been generated by other contemporaneous events, as those would have to be differentially relevant for people with different strengths of preference for the outcome of the referendum to understand the results reported in Table 3. Interestingly, even for those who claimed (before the referendum) to be indifferent we find a non-negligible winner-loser effect in the same direction as for the other groups (that this effect is only significant at the $10 \%$ level reflects also the limited number of cases in this group). This may either reflect that these respondents were not entirely indifferent, or that the mere fact of being in the 'winning' group has a positive impact on perceived referendum fairness.

The second potential problem with attributing the effects reported in Table 2 (and Table 3) to being on the winning or losing side of the outcome, is that expectations about the outcome may have influenced pre-referendum responses to the fairness question, thereby introducing an element of endogeneity in the analyses. The potential presence of such endogeneity can be assessed in multiple ways using respondents' expectation of which side would win the referendum, which was asked in wave 7 (pre-referendum). ${ }^{7}$ The respective analyses (reported in Section 4 of the Supplementary Materials for the sake of brevity) do not provide any support to the notion that our main results (reported in Table 2) are an artefact of, or biased by, endogeneity.

As stated earlier, the referendum fairness questions were not only asked immediately after the referendum, but also 5 months and 10 months later. We can thus test whether the winner-loser effect

\footnotetext{
${ }^{6}$ This question was included in the questionnaire for only a random subset of about 25 percent of all respondents in wave 7. The combined size of the groups in Table 3 is therefore smaller than the $n$ reported in Table 2. This does not affect the relevance of these analyses.

${ }^{7}$ The same expectation question was also included in the questionnaire of wave 8 (which was conducted during the 'hot' phase of the campaign). Using the wave 8 information instead of the responses from wave 7 gives rise to the same conclusions as reported here.
} 
decreases, remains the same, or increases over time. Were it to decrease, this would signify that that the outcome of the referendum has gradually become the 'new normal', and that the referendum outcome gets gradually 'accepted' by the losers. Were the winner-loser effect to increase over time, it would reflect continued and increased politicisation of the legitimacy of the outcome and nonacceptance of the outcome by the losing side. Table 4 reports the magnitude of the winner-loser effects based on d-i-d analyses on different time intervals (full results in Section 5 of Supplementary Materials).

Table 4 Magnitude of winner-loser effect on perceived referendum fairness for different time intervals

\begin{tabular}{lcccc}
\hline Time period & $\begin{array}{c}\text { D-i-d (winner- } \\
\text { loser) effect }\end{array}$ & $\begin{array}{c}\text { Standard } \\
\text { error }\end{array}$ & $\mathbf{P}$ & $\begin{array}{c}\mathbf{N} \\
\text { (weighted) }\end{array}$ \\
\hline $\begin{array}{l}\text { wave 7 (pre-referendum) - wave } \\
9 \text { (immediately post referendum) }\end{array}$ & -1.673 & 0.058 & $<.0005$ & $7593-7984$ \\
$\begin{array}{l}\text { wave 7 (pre-referendum) - wave } \\
10 \text { (5 months after referendum) }\end{array}$ & -2.179 & 0.062 & $<.0005$ & $7593-7960$ \\
$\begin{array}{l}\text { wave 7 (pre-referendum) - wave } \\
11 \text { (10 months after referendum) }\end{array}$ & -2.360 & 0.059 & $<.0005$ & $7593-8043$ \\
\hline
\end{tabular}

Note: Winner-loser groups defined on referendum vote (leave vs. remain voters); pre-referendum and postreferendum observations from BESIP (weaves 7 and 9); with covariates specified in text; only respondents who participated in all four waves $(7,9,10,11)$; clustered standard errors; weighted data

The analyses clearly demonstrate that, even 10 months after the referendum, the outcome had not been 'accepted' by the losers in any meaningful way. On the contrary, their perception that the referendum had been conducted unfairly has been strengthened considerably. It is, of course, impossible to determine to what extent this also reflects the ongoing contestation about the desired character of Brexit and the gradually emerging flow of new information suggesting that the conduct of the referendum was marred by real improprieties (campaigns exceeding legal spending limits; questions about the legality of donor contributions; social media meddling from abroad; etc.) which may affect perceptions of referendum fairness.

As discussed earlier, studies of winner-loser effects in the extant literature generally focus on elections, not on referenda. The question therefore arises how these findings compare with similar findings relating to general elections. Because the same questions about fairness have been asked with respect to the General Election of 2017, we can address this question directly. This puts the winner-loser effects on perceived referendum fairness in a broader perspective, and also tests our expectation that these effects are larger in a contentious constitutional referendum than in a regular election. The questions about perceived fairness of the way the general election is conducted were asked in BESIP waves 11 and 13. Wave 11 was fielded between 24 April and 3 May 2017, shortly before the election of 8 June. Wave 13 took place immediately following that election, between 9 and 23 June 2017. In terms of this election winners were voters for the Conservative party, and losers were voters for all other parties. ${ }^{8}$ The winner-loser effect from a $d-i-d$ analysis for these data is 0.630

\footnotetext{
${ }^{8}$ This definition is in line with the extant literature that defines winners as the voters for parties that acquired government power because of the election.
} 
$(p<.0005) .{ }^{9}$ In short, there is a significant, but more moderately sized winner-loser effect in the General Election. This comparison supports our expectations that contentious referenda are likely to generate much larger winner-loser effects than generally observed in the context of regular elections.

\section{Discussion and conclusions}

Our analyses demonstrate that worryingly large groups of British citizens have rather dim views of the fairness of electoral processes in the UK. Compared to the (unlikely) normative ideal of all citizens seeing electoral competitions as fair, we find less than $50 \%$ of respondents express this view in the case of the EU referendum. The results also demonstrate that beliefs about the fairness of the referendum changed strongly (and in opposite directions) for leave and remain supporters because of the referendum outcome, representing a large decline for remain supporters in absolute terms. Given the extant literature, a winner-loser effect was expected. Previous research generally reports winnerloser effects of around 5-10\% of the range of the outcome variable (Singh at al., 2011: 704; Rose, 2014: 84). Yet in the case of the EU referendum, we find effects far larger (and also far larger than we found for the general election of 2017). Indeed, for the EU referendum the winner-loser effect is $33 \%$ of the range of the outcome variable, and over $50 \%$ for the (relatively large) group who cared most about the outcome of the referendum. These are winner-loser differences of an unprecedented magnitude. Furthermore, this effect did not dissipate over time, but instead grew importantly over the course of the first year after the referendum. These results demonstrate that the leave and remain sides have not 'come together' since the vote. As this division concerns a base evaluation of the fairness of the vote, rather than a measure of satisfaction with the outcome, this cleavage also reflects that the legitimacy of the referendum and its outcome have become both hotly contested and politicised. That makes it unlikely that leave and remain supporters will easily 'come together' in the future, irrespective of how Brexit will proceed. A similar conclusion has also been reached by Evans and Schaffner (2019) who analysed political identities. They found that leave and remain have evolved into central aspects of citizens' political identity, held with great social and emotional intensity, and likely to remain important drivers of political orientation. Our analyses not only affirm the existence of these rivalling identities but supplement it by demonstrating that they are also the basis for political contestation about the legitimacy of the referendum and its outcome. This latter aspect has the potential to undermine the consent of the governed upon which democratic governance rests, at least for a significant part of the population. Moreover, this contestation may provide the context in which future trade negotiations, which will determine the form that Brexit takes, will be understood by the public.

What, if any, conclusions can be drawn from our analyses for other referenda? Or is the $2016 \mathrm{EU}$ referendum a sui generis event that does not lend itself to sensible generalisation? In our view, this referendum is not a unique case; instead, on the basis of Gerring's (2008) discussion of case selection for case study analysis, the EU referendum can be considered as an almost ideal-typical case of a broader universe of referenda that is characterised by (a) being highly emotive for large segments of the electorate; (b) appealing to (and giving rise to) exclusive political identities strongly

\footnotetext{
${ }^{9}$ Detailed results are reported in Section 6 of the online Supplementary Materials, which also include the distributions of these questions about the fairness of the General Election. Although it is not our focus in this study, it should be noted that the percentage of 'unfair' responses is $23 \%$ (before) and 25\% (after the General Election). While this is lower than for the referendum (see Table 1) it is considerably higher than for the same question asked prior to the 2015 General Election (16\%), and much higher than a very similar question asked in the BES of 1997 (4\%) (CREST, 1999).
} 
amplified by regular or social media; with (c) neither side having a large majority; and (d) with farreaching and enduring consequences for the organisation of the polity at large. Based on these criteria, the 'Brexit' referendum belongs to the same class of referenda as the 1995 Quebec independence referendum (Sklar, 1999), the 2014 Scottish independence referendum (Dekavalla, 2018) , the 2017 Turkish constitutional referendum (Furman and Tunç, 2019), the 1950 Belgian monarchy referendum (van den Wijngaert, 2001), and yet others. For referenda of this kind our analyses demonstrate that the idea they are useful instruments to come to a solution for political problems that are beyond the capacity of parties and politicians is overly simplistic. ${ }^{10}$ Indeed, when such problems become heavily politicised (as in the case with the EU referendum) referenda aggravate the problem rather than solve it, particularly when they contribute to contestation about the legitimacy of electoral processes. Without sufficient agreement about the legitimacy of these central processes of popular political involvement, no democratic rule can survive (Miller, 1974: 951). This also implies that, irrespective of how the Brexit process will play out, British parties and politicians have an urgent responsibility to restore widely shared confidence in the fairness of electoral processes.

Our analyses also demonstrate that our discipline has too long disregarded how citizens perceive and experience the fairness of elections. The most recent previous election study about this in the UK was more than two decades ago and contained just a single relevant question. The BES Internet Panel has had the wisdom to not only repeat that single question, but to complement it with related questions, and with repeat observations at different moments and for different kinds of elections. In view of both the severe winner-loser effects that we identified and the worryingly large groups that express doubts about the fairness of electoral processes, we can no longer take for granted that elections generate their own legitimacy. We hope therefore that in the future more surveys will include the kind of questions we analysed here, and expand on them.

\footnotetext{
${ }^{10}$ The potential of referenda to weaken the health of the democratic system has been explicitly acknowledged in the report of the Independent Commission on Referendums (2018).
} 


\section{Bibliography}

Anderson, C. et al. (2005) Losers' Consent: Elections and Democratic Legitimacy. Oxford: Oxford University Press.

Anderson, C. J., and Guillory, C. A. (1997). Political institutions and satisfaction with democracy: A cross-national analysis of consensus and majoritarian systems. American Political Science Review, 91(1), 66-81.

Anderson, C. and LoTempio, A. (2002) Winning, Losing and Political Trust in America. British Journal of Political Science, 32(2), pp.335-351.

Angrist, J.D., and Pischke, J-S. (2009) Mostly Harmless Econometrics. New York: Princeton University Press.

Beaudonnet, L., at al. (2014). The impact of election outcomes on satisfaction with democracy under a two-round system. French Politics, 12(1), 22-35.

Birch, S. (2010). Perceptions of Electoral Fairness and Voter Turnout. Comparative Political Studies, 43(12), 1601-1622.

Blais, A. and Gélineau, F. (2007) Winning, Losing and Satisfaction with Democracy. Political Studies, 55(2), pp.425-441.

Bowler, S., et al., (2015). Election Administration and Perceptions of Fair Elections. Electoral Studies, 38, 1-9.

Buchanan, A. (2002). Political legitimacy and democracy. Ethics, 112(4), 689-719.

de Chaisemartin C. and D'Haultfeuille X. (2018). Fuzzy Differences-in-Differences. Review of Economic Studies 85, 999-1028.

CREST (Centre for Research into Elections and Social Trends) (1999). 1997 British General Election Study: Cross-section study, Scottish election study, Ethnic Minority study-Codebook. London: CREST.

Dekavalla, M. (2018). Issue and game frames in the news: Frame-building factors in television coverage of the 2014 Scottish independence referendum. Journalism, 19(11), 1588-1607.

Delgado, I. (2016). How governing experience conditions winner-loser effects. An empirical analysis of the satisfaction with democracy in Spain after 2011 elections. Electoral Studies, 44, 76-84.

Easton, D. (1965) A Systems Analysis of Political Life. New York: Wiley.

van der Eijk, C., and Franklin, M. (2009). Elections and Voters. (Basingstoke: Palgrave).

Esaiasson, P. (2011) Electoral Losers Revisited - How Citizens React to Defeat at the Ballot Box, Electoral Studies, 30(1), 102-113.

Esaiasson, P., et al., (2019). Reconsidering the role of procedures for decision acceptance. British Journal of Political Science, 49(1), 291-314.

Evans, G. And Schaffner, F. (2019). Brexit Identities: how Leave versus remain replaced Conservative versus Labour affiliations of British voters. https://ukandeu.ac.uk/brexit-identities-how-leave-versusremain-replaced-conservative-versus-labour-affiliations-of-british-voters/ (Accessed 3 May 2020). 
Ezrow, L., and Xezonakis, G. (2016). Satisfaction with Democracy and Voter Turnout: A temporal perspective. Party Politics, 22(1), 3-14.

Fieldhouse, E., J. Green., G. Evans., H. Schmitt, C. van der Eijk, J. Mellon and C. Prosser (2018) British Election Study Internet Panel Waves 1-14. https://www.britishelectionstudy.com/wpcontent/uploads/2018/09/Bes_wave14Documentation_V1.pdf (Accessed 3 May 2020).

Franck, T.M. (1992). The Emerging Right to Democratic Governance. The American Journal of International Law 86(1), 46-91.

Fricke H. (2017) Identification based on Difference-in-Differences Approaches with Multiple Treatments. Oxford Bulletin of Economics and Statistics, 79(3),426-433.

Furman I. and Tunç, A. (2019). The End of the Habermassian Ideal? Political Communication on Twitter During the 2017 Turkish Constitutional Referendum. Policy and Internet, doi.org/10.1002/poi3.218 (Accessed 3 May 2020).

Gerring J. (2008). Case selection for case-study analysis: qualitative and quantitative techniques. In: Janet M. Box-Steffensmeier, Henry E. Brady and David Collier (eds) Oxford Handbook of Political Methodology, 645-684.

Hackman J.R., Pearce J.L. and Wolfe, J.C (1978) Effects of Changes in Job Characteristics on Work Attitudes and Behaviors: A naturally occurring quasi-experiment. Organizational Behavior and Human Performance, 21, 289-304.

Han, S. M., and Chang, E. C. (2016). Economic inequality, winner-loser gap, and satisfaction with democracy. Electoral Studies, 44, 85-97.

Hellevik O. (2009). Linear versus Logistic Regression when the Dependent Variable is a Dichotomy. Quality and Quantity, 43, 59-74.

Howell, P., and Justwan, F. (2013). Nail-biters and no-contests: The effect of electoral margins on satisfaction with democracy in winners and losers. Electoral Studies, 32(2), 334-343.

Imbens, G.W., and Rubin, D.B. (2015) Causal Inference in Statistics, Social and Biomedical Sciences. Cambridge: Cambridge University Press.

Imbens, G.W., and Wooldridge, J.M., (2009). Recent Developments in the Econometrics of Program Evaluation. Journal of Economic Literature, 47, 5-86.

Independent Commission on Referendums (2018). Report of the Independent Commission on Referendums. London: Constitution Unit, School of Public Policy, University College London, https://www.ucl.ac.uk/constitution-unit/sites/constitution-unit/files/182__independent_commission_on_referendums.pdf (accessed 3 May 2020).

Lechner M. (2011) The Estimation of Causal Effects by Difference-in-Difference Methods. Foundations and Trends in Econometrics, 4, 165-224.

Leiter, D., Clark, A. K., \& Clark, M. (2019). Winners and losers reconsidered: party support, character valence, and satisfaction with democracy. European Political Science Review, 11(3), 285-300.

Linde, J., and Ekman, J. (2003). Satisfaction with democracy: A note on a frequently used indicator in comparative politics. European Journal of Political Research, 42(3), 391-408. 
Locke, J. (1821 [1689]) Two Treatises of Government: A New Edition Corrected. London: Whitmore and Fenn.

Marien, S., and Kern, A. (2018). The winner takes it all: Revisiting the effect of direct democracy on citizens' political support. Political Behavior, 40(4), 857-882.

Martin, A., Mikołajczak, G., \& Orr, R. (2020). Does process matter? Experimental evidence on the effect of procedural fairness on citizens' evaluations of policy outcomes. International Political Science Review. https://doi.org/10.1177/0192512120908874 (Accessed 3 May 2020).

Martini, S., and Quaranta, M. (2019). Political support among winners and losers: Within-and between-country effects of structure, process and performance in Europe. European Journal of Political Research, 58(1), 341-361.

van der Meer, T. W., and Steenvoorden, E. H. (2018). Going back to the well: A panel study into the election boost of political support among electoral winners and losers. Electoral Studies, 55, 40-53.

Miller, A. H. (1974). Political issues and trust in government: 1964-1970. American Political Science Review, 68(3), 951-972.

Mokken, R.J. (1971). A Theory and Procedure of Scale Analysis. (The Hague: Mouton).

Nagin, D. S., and Telep, C. W. (2017). Procedural justice and legal compliance. Annual Review of Law and Social Science, 13, 5-28.

Niesiobędzka, M., and Kołodziej, S. (2017). The Fair Process Effect in Taxation: The roles of procedural fairness, outcome favorability and outcome fairness in the acceptance of tax authority decisions. Current Psychology, 1-8.

Rose, J. (2014). The Public Understanding of Political Integrity: The case for probity perceptions. (Basingstoke: Palgrave).

Scholz, J. T., and Lubell, M. (1998). Trust and taxpaying: Testing the heuristic approach to collective action. American Journal of Political Science, 42(2), 398-417.

van Schuur W.H. (2011) Ordinal Item Response Theory: Mokken Scale Analysis. London: Sage.

Shadish, W.R., Cook T.D. and Campbell D.T. (2002). Experimental and Quasi-Experimental Designs for Generalized Causal Inference. Boston: Houghton Mifflin.

Singh, S., Lago, I., and Blais, A. (2011). Winning and competitiveness as determinants of political support. Social Science Quarterly, 92(3), 695-709.

Singh, S., Karakoç, E., and Blais, A. (2012). Differentiating winners: How elections affect satisfaction with democracy. Electoral Studies, 31(1), 201-211.

Sklar, A. (1999) Contested collectives: The struggle to define the "we" in the 1995 Québec referendum. Southern Communication Journal, 64:2, 106-122.

Sunshine, J., and Tyler, T. R. (2003). The role of procedural justice and legitimacy in shaping public support for policing. Law \& Society Review, 37(3), 513-548.

Tyler, T. R. (1988). What is procedural justice-criteria used by citizens to assess the fairness of legal procedures. Law \& Society Review, 22, 103-135. 
Tyler, T. R. (2003). Procedural justice, legitimacy, and the effective rule of law. Crime and Justice, 30, 283-357.

Tyler, T. R., and Rasinski, K. (1991). Procedural justice, institutional legitimacy, and the acceptance of unpopular US Supreme Court decisions: A reply to Gibson. Law and Society Review, 25(3), 621-630.

Villa J.M. 2016. Diff: Simplifying the Estimation of Difference-in-Differences Treatment Effects. The Stata Journal, 16, 52-71.

van den Wijngaert, M. (2001). De volksraadpleging van 12 maart 1950. In F. Fleerackers (red.), De Re Ferenda: Een meta-juridische conflictanalyse van het referendum. Brussels: Larcier, pp.131-144.

Wing C., K. Simon and R.A. Bello-Gomez. 2018. Designing Difference in Difference Studies: Best Practices for Public Health Policy Research. Annual Review of Public Health 39, 453-469. 


\section{Supplementary Materials for \\ Winner-loser effects in contentious constitutional referenda - perceptions of procedural fairness and the Brexit referendum}

These supplementary materials comprise the following information that is referred to in the main article:

1. Details of variables used for comparisons or for covariates

2. A test of the 'parallel trend assumption' that underlies $d$-i-d analyses

3. Details of the analyses summarised in Table 3 of the main text

4. Test of endogeneity as a result of pre-referendum expectations of the outcome

5. Details of the analyses summarised in Table 4 of the main text

6. Details of the winner-loser effect on perceptions of fairness of the General Election of 2017

7. Stata code for replication purposes

\section{Details of variables used for comparisons or for covariates}

Variables used as covariates in $d-i-d$ analyses

distributions below are unweighted for respondents taking part in all four waves $(7.9,10,11)$

- Gender male (coded 1; 49.9\%); female (coded 2; 50.1\%)

- Age coded as reported age (in full years) in 2014; range 15-90, mean 51.7, s.d. 14.8

- Education coded as age (in full years) when respondent left full time education; categories $=<15(12.1 \%)$, 16 (24.0\%), 17-18 (21.7\%), 19 (4.3\%), >=20 (33.4\%). 'Still at school/Fulltime student' and 'can't remember' coded as missing (4.5\%).

- Ethnicity dichotomy with 'white British' and 'any other white background' coded 1 (94.9\%) and every other category 2 (5.1\%).

- Nationality coded as dummies for Scotland (13.9\%) and Wales (7.9\%), with England (78.2\%) as reference category

- Social grade coded as separate dummies for A (13.3\%), B (19.3\%), C1 (26.4\%), C2 (16.5\%), D (9.5\%) and E (used as reference category in the analyses, $13.0 \%$ ). Missing values $2.0 \%$ 
- "How will you feel if Britain votes to leave the EU?" (asked in wave 7 to a random subgroup of the entire sample of that wave). Distribution of the non-missing cases: 1: very unhappy (21.3\%), 2: somewhat unhappy (13.3\%), 3: a little unhappy (9.5\%), 4: indifferent (11.0\%), 5: a little happy (9.1\%), 6: somewhat happy (11.5\%), 7: very happy (24.2\%).

\section{Perceptions of Fairness of the 2017 General Election}

distributions below are unweighted for all respondents taking part in the respective waves in which the questions were asked

- "How fairly do you expect the General Election to be conducted?", Asked in wave 2 (before the 2015 General Election, only for a random subgroup of cases) and in wave 11 (before the 2017 General Election).

- "How fairly do you think the General Election was conducted?", asked in wave 13 (after the General Election of 2017).

\begin{tabular}{lccc}
\hline & Wave 2 & Wave 11 & Wave 13 \\
\hline 1 fairly & $38.2 \%$ & 32.25 & $30.3 \%$ \\
2 & $23.6 \%$ & $18.1 \%$ & $18.7 \%$ \\
3 & $20.7 \%$ & $22.8 \%$ & $23.9 \%$ \\
4 & $10.5 \%$ & $14.8 \%$ & $16.0 \%$ \\
5 unfairly & $7.0 \%$ & $12.1 \%$ & $11.0 \%$ \\
\hline
\end{tabular}

\section{A test of the 'parallel trend assumption' that underlies $d-i-d$ analyses}

The central assumption of difference-in-differences analysis is the so-called parallel trend assumption. This assumption holds that, if the event in question (i.e., the EU referendum) had not occurred, the difference between the average scores of the two groups (the leave-voters and the remain-voters) would be the same at different moments in time.

The 'not occurred' condition is only true before the event, and testing this assumption empirically therefore requires multiple pre-referendum measurements of the question about its fairness. Unfortunately, the fairness question was only asked once before the referendum, in wave 7. However, BESIP contains another question that can be used as a proxy and that has been used in (almost) all waves of BESIP, namely the standard question about satisfaction with democracy that has been used frequently in the extant literature as dependent variable in analyses of winner-loser gaps. The question is formulated as follows: "On the whole, how satisfied or dissatisfied are you with the way that democracy works in The UK as a whole", the response options are "very dissatisfied", "a little dissatisfied", "fairly satisfied" and "very satisfied" (while respondents could also indicate "don't know").

The relevance of a test of the parallel trend assumptions based on the satisfaction with democracy question rests on three conditions:

1. The satisfaction with democracy question should be a plausible proxy for the fairness of the referendum question.

Conceptually, both questions refer to how well, in the respondent's view, politics works. Satisfaction with democracy is wider and less specific, while the fairness of the referendum 
question is narrower and more specific. Yet, both questions have been applied to studies of winner-loser effects (such as by, for example, Anderson et al. (2005) in their analyses of Loser's Consent).

Empirically, responses to both questions are positively correlated. In the wave 7 data, which contain both questions, their association is 0.32 expressed in terms of Loevinger's coefficient of homogeneity, which is slightly above the generally regarded lowerbound $(0.3)$ for considering them as sharing overlapping latent meaning in the understanding of respondents (Mokken 1971; Van Schuur 2005).

In short, the satisfaction with democracy is a plausible proxy, both in conceptual and empirical terms.

2. When using the satisfaction with democracy question, we should observe a significant winnerloser effect in the same direction as we did when using the referendum fairness question as dependent variable and comparing responses from before to responses after the EU referendum.

As shown in Table A1 this is indeed the case. This table can be compared to Table 2 in the main text, and we see that the groups change in the same way as in Table 2 (leave voters becoming more positive, remain voters less positive), switching positions. ${ }^{11}$ The $\mathrm{d}$-i-d effect is 0.47 , which is about $12 \%$ of the range of the dependent variable (range 1-4); this is substantively smaller than the effect we found for the referendum fairness question, where the effect was 1.67 (i.e., 33\% of the range of 1-5). But more important is that responses to satisfaction with democracy change for both groups in a very similar way as responses to the referendum fairness question when comparing them before and after the EU referendum.

Table A1 Differences-in-differences analysis of responses to satisfaction with democracy question in wave 7 (before EU referendum) and wave 9 (after EU referendum)

\begin{tabular}{|c|c|c|c|c|}
\hline & $\begin{array}{l}\text { Estimated mean on } \\
\text { satisfaction with } \\
\text { democracy question } \\
\text { (1=very dissatisfied; } \\
\text { 5=very satisfied) }\end{array}$ & $\begin{array}{l}\text { standard } \\
\text { error }\end{array}$ & $|t|$ & $p$ \\
\hline \multicolumn{5}{|l|}{ Before referendum (wave 7) } \\
\hline Remain voters & 2.057 & & & \\
\hline Leave voters & 1.916 & & & \\
\hline Difference & -0.141 & 0.029 & -4.84 & $<.0005$ \\
\hline \multicolumn{5}{|l|}{ After referendum (wave 9) } \\
\hline Remain voters & 1.770 & & & \\
\hline Leave voters & 2.101 & & & \\
\hline Difference & 0.331 & 0.031 & 10.71 & $<.0005$ \\
\hline Difference-in-difference & 0.472 & 0.029 & 16.26 & $<.0005$ \\
\hline
\end{tabular}

\footnotetext{
${ }^{11}$ These results are virtually unaffected by weighting or not weighting, or by restricting the analyses only to those who took part in all four waves 7, 9, 10 and 11, or to only those who took part in both waves 7 and 9 .
} 
3. When using the satisfaction with democracy question, we should observe no significant winner-loser effect when comparing responses at two different times that are both before the referendum. To make this so-called placebo test as demanding as possible, we chose to use BESIP waves 1 and 2, which took place in a political context with relevant similarities to the 2016 period around the EU referendum. Wave 1 took place between 20th February 2014 and 9th March 2014, which is shortly before the European Parliament elections of 22 May 2014. Wave 2 was fielded immediately following these elections, between 22 May and 25 June. The relevance of these two waves, and the election that separates them, is that this period was, just like the referendum period in 2016, heavily focused on British membership of the EU, with UKIP obtaining the largest vote share of all parties. It would therefore be quite conceivable that those who would vote two years later for leave (or remain) would already in 2014 consider themselves as winners (or losers) of the European Parliament election. That would falsify the parallel trend assumption, and thus cast doubt on the interpretation of the $d$-i-d effect on the question about referendum fairness (reported in the main text) as a consequence of the $\mathbf{2 0 1 6}$ referendum. Instead it would signify that the two groups were not 'created' by the outcome of the referendum, but had already been formed earlier, which would mean that the $d$-i-d effect was, at least to some extent, endogenous. Table A2 presents the full results of the analyses; it shows no significant $d$-i-d effect whatsoever (which is all the more convincing because the large number of cases tends to easily make a substantively small effect statistically significant). Thus, the parallel trend assumption is strongly supported, making endogeneity threats to the interpretation of our findings implausible.

Table A2 Differences-in-differences placebo analysis of responses to satisfaction with democracy question in wave 1 (before European Parliament election 2014) and wave 2 (after European Parliament election 2014)

\begin{tabular}{|c|c|c|c|c|}
\hline & $\begin{array}{l}\text { Estimated mean on } \\
\text { satisfaction with } \\
\text { democracy question } \\
\text { (1=very dissatisfied; } \\
\text { 5=very satisfied) }\end{array}$ & $\begin{array}{l}\text { standard } \\
\text { error }\end{array}$ & $|t|$ & $\mathrm{p}$ \\
\hline \multicolumn{5}{|l|}{ Before referendum (wave 1 ) } \\
\hline Remain voters & 2.008 & & & \\
\hline Leave voters & 1.800 & & & \\
\hline Difference & -0.208 & 0.032 & 6.54 & $<.0005$ \\
\hline \multicolumn{5}{|l|}{ Before referendum (wave 2) } \\
\hline Remain voters & 1.961 & & & \\
\hline Leave voters & 1.759 & & & \\
\hline Difference & -0.203 & 0.032 & 6.43 & $<.0005$ \\
\hline Difference-in-difference & 0.005 & 0.032 & 0.15 & 0.882 \\
\hline
\end{tabular}




\section{Details of the analyses summarised in Table 3 of the main text}

Table 3 of the main text summarises the $d-i-d$ analyses by only reporting the $d$-i-d effect estimate. The full set of results is reported in Tables $A 3$ to $A 6$.

Note for all these tables: Winner-loser groups defined on referendum vote (leave voters vs remain voters); wave7 and wave9 data from BESIP; with covariates specified in text; clustered standard errors; only respondents who participated in all four waves $(7,9,10,11)$; weighted data (numbers of cases included in the analyses (see also footnote 5 of main text): for TableA3: 841-869; for Table A4: 445-450; for Table A5: 342-351; for Table A6: 155-158).

Table A3 Differences-in-differences analysis of responses to fairness of the EU Referendum in wave 7 (before the EU referendum) and wave 9 (after the EU referendum)

Only respondents stating (in wave 7) that they would be very (un)happy with 'leave'

\begin{tabular}{ccccc}
\hline & $\begin{array}{c}\text { Estimated mean on } \\
\text { question about fairness } \\
\text { of how the EU } \\
\text { referendum is conducted } \\
\text { (1=fair; 5=unfair) }\end{array}$ & $\begin{array}{c}\text { standard } \\
\text { error }\end{array}$ & $|\mathrm{t}|$ & $\mathrm{p}$ \\
\hline Before Referendum (wave 7) & 1.286 & & & \\
Remain voters & 2.722 & & & \\
Leave voters & 1.436 & 0.130 & & \\
Difference & & & \\
After Referendum (wave 9) & 2.830 & & \\
Remain voters & 1.679 & & \\
Leave voters & -1.151 & 0.147 & $<.0005$ \\
Difference & -2.587 & 0.156 & $<.0005$ \\
\hline
\end{tabular}

Table A4 Differences-in-differences analysis of responses to fairness of the EU Referendum in wave $\mathbf{7}$ (before the EU referendum) and wave 9 (after the EU referendum)

Only respondents stating (in wave 7) that they would be somewhat (un)happy with 'leave'

\begin{tabular}{cccccc}
\hline & $\begin{array}{c}\text { Estimated mean on } \\
\text { question about fairness } \\
\text { of how the EU } \\
\text { referendum is conducted } \\
\text { (1=fair; 5=unfair) }\end{array}$ & $\begin{array}{c}\text { standard } \\
\text { error }\end{array}$ & $|\mathrm{t}|$ & $\mathrm{p}$ \\
\hline Before Referendum (wave 7) & 3.252 & & & \\
Remain voters & 4.133 & & & \\
Leave voters & 0.881 & 0.148 & 5.96 & $<.0005$ \\
Difference & & & & \\
After Referendum (wave 9) & 4.214 & & & \\
Remain voters & 3.380 & & & \\
Leave voters & -0.833 & 0.178 & 4.68 & $<.0005$ \\
Difference & -1.715 & 0.217 & 7.91 & $<.0005$ \\
\hline
\end{tabular}


Table A5 Differences-in-differences analysis of responses to fairness of the EU Referendum in wave 7 (before the EU referendum) and wave 9 (after the EU referendum)

Only respondents stating (in wave 7) that they would be a little (un)happy with 'leave'

\begin{tabular}{cccccc}
\hline & $\begin{array}{c}\text { Estimated mean on } \\
\text { question about fairness } \\
\text { of how the EU } \\
\text { referendum is conducted } \\
\text { (1=fair; 5=unfair) }\end{array}$ & $\begin{array}{c}\text { standard } \\
\text { error }\end{array}$ & $|\mathrm{t}|$ & $\mathrm{p}$ \\
\hline Before Referendum (wave 7) & & & & & \\
Remain voters & 2.072 & & & \\
Leave voters & 2.285 & 0.191 & 1.12 & .263 \\
Difference & 0.214 & & & \\
After Referendum (wave 9) & & & & \\
Remain voters & 2.768 & & & \\
Leave voters & 1.987 & 0.227 & 3.44 & $<.001$ \\
Difference & -0.781 & 0.290 & 3.43 & $<.001$ \\
\hline
\end{tabular}

Table A6 Differences-in-differences analysis of responses to fairness of the EU Referendum in wave $\mathbf{7}$ (before the EU referendum) and wave 9 (after the EU referendum)

Only respondents stating (in wave 7) that they would be indifferent about 'leave'

\begin{tabular}{cccccc}
\hline & $\begin{array}{c}\text { Estimated mean on } \\
\text { question about fairness } \\
\text { of how the EU } \\
\text { referendum is conducted } \\
\text { (1=fair; 5=unfair) }\end{array}$ & $\begin{array}{c}\text { standard } \\
\text { error }\end{array}$ & $|\mathrm{t}|$ & $\mathrm{p}$ \\
\hline $\begin{array}{c}\text { Before Referendum (wave 7) } \\
\text { Remain voters }\end{array}$ & 3.827 & & & \\
Leave voters & 3.954 & & & \\
Difference & 0.127 & 0.222 & 0.57 & $<.567$ \\
After Referendum (wave 9) & & & & \\
Remain voters & 4.112 & & & \\
Leave voters & 3.736 & & & \\
Difference & -0.376 & 1.48 & & $<.142$ \\
Difference-in-difference & -0.503 & 1.75 & & $<.083$ \\
\hline
\end{tabular}

\section{Test of endogeneity as a result of pre-referendum expectations of the outcome}

The interpreted the findings reported in Tables 23 to being on the winning or losing side of the outcome. A potential problem, which could lead to a specific form of endogeneity, is that expectations about the outcome may have influenced pre-referendum responses to the fairness question, so that these pre-referendum responses would not be independent of the eventual outcome, as assumed in $\mathrm{d}-\mathrm{i}-\mathrm{d}$ analyses. We can assess such potential endogeneity on the basis of a question that was asked before the referendum, in wave 7, about respondents' expectation of which 
side would win the referendum. ${ }^{12}$ This information can be used in different ways, of which we elaborate two below, but which both give rise to the same substantive conclusion: there is no evidence whatsoever that expectations about the outcome were already 'factored in' in the responses to the question about the fairness of the referendum.

\subsection{Testing observable implications of possible expectations effects}

If expectations about the outcome would have been factored in in the response to the referendum fairness question, then this would give rise to two sets of observable implications. First:

- Leavers wo expect their side to win would see the referendum as more fair (before the referendum took place) then Leavers who expect their side to lose;

- Remainers who expect their side to win would see the referendum as more fair (before the referendum took place) than Remainers who expect their side to lose.

A second set of observable implications would be that:

- winners (Leavers) who had expected (before the referendum) to win make smaller gains between W7 and W9 in the outcome variable than winners who had expected to lose.

- Similarly, Losers (Remainers) who had expected (before the referendum to lose), experience a smaller drop in the outcome variable than losers who had expected to win.

The first set of observable implications can be tested by correlating, separately for Leavers and Remainers, their expectation of the outcome, and their expected fairness of the referendum. For Leavers this correlation is $0.10(n=8794)$ and for Remainers it is $0.09(n=8745)$. Neither correlation is very strong but given the large $n$ they are statistically different from zero $(p<.01)$. However, given the way the variables are coded, the first of these correlations is in the 'wrong' direction: the more that Leavers expect that Leave will win, the higher their score on fairness question, which means the more they expect the referendum to be unfair! The other correlation is in the expected direction.

The second set of observable implications can be tested by correlating two variables (again, separately for Leavers and Remainers): on the one hand the change (from wave7 to wave9) in the response to the referendum fairness question, and on the other hand a transformation of the expectation of the outcome question, so that it reflects how likely it is that one's own side is expected to win the referendum. For Leavers this correlation is 0.09 , for Remainers it is -0.07 . Again, both correlations are significant, but weak. And again, one of these correlations is in the wrong direction as the first of these correlations indicates that Leavers who expected to win make larger gains in the perceived 'fairness' than those who expected to lose, which runs entirely against the grain of the observable implications formulated above.

Taking these results together does not give any compelling support for a suspicion of endogeneity. ${ }^{13}$

\subsection{Using expectations as a covariate in the $d-i-d$ analyses}

As described in the main text (section about Analytical Approach), a d-i-d analysis can include covariates, which operate on the estimation of the mean scores (before and after) on perceived referendum fairness of the two groups function (these mean scores, in turn, lie at the basis of the

\footnotetext{
12. The same expectation question was also included in the questionnaire of wave 8 (which was conducted during the 'hot' phase of the campaign). Using the wave 8 information instead of the responses from wave 7 gives rise to the same conclusions as reported here.

${ }^{13}$ These conclusions do not change when controlling for other characteristics of respondents, such as the variables described in section 1 of this online Supplementary Material.
} 
calculation of the $\mathrm{d}$-i-d effect). It is this possible to add expectations of the outcome as a covariate to the analysis that is reported in Table 2 of the main text. As reported in Table 2, the d-i-d effect without this extra covariate is -1.673 (standard error 0.058 ); when including the expectation of the outcome as an additional covariate the $d$-i-d effect is -1.670 (standard error 0.061 ). Thus, controlling for pre-referendum expectations of which side would win, leads to a d-i-d effect that is statistically indistinguishable from the effect obtained when not controlling for these expectations.

\section{Details of the analyses summarised in Table 4 of the main text}

Table 3 of the main text summarises the $d-i-d$ analyses by only reporting the $d$-i-d effect estimate. The full set of results is reported in Tables A7 to A9.

Note for all these tables: Winner-loser groups defined on referendum vote (leave voters vs remain voters); wave7 and wave9 data from BESIP; with covariates specified in text; clustered standard errors; only respondents who participated in all four waves $(7,9,10,11)$; weighted data (numbers of cases included in the analyses --see also footnote 5 of main text: for TableA7: 7593-7984; for Table A8: 7593-7960; for Table A9: 7593-8043).

Table A7 Differences-in-differences analysis of responses to fairness of the EU Referendum in wave 7 (before the EU referendum) and wave 9 (after the EU referendum)

\begin{tabular}{cccccc}
\hline & $\begin{array}{c}\text { Estimated mean on } \\
\text { question about fairness } \\
\text { of how the EU } \\
\text { referendum is conducted } \\
\text { (1=fair; 5=unfair) }\end{array}$ & $\begin{array}{c}\text { standard } \\
\text { error }\end{array}$ & $|\mathrm{t}|$ & $\mathrm{p}$ \\
\hline Before Referendum (wave 7) & & & & & \\
Remain voters & 2.717 & & & \\
Leave voters & 3.540 & 0.047 & 17.57 & $<.0005$ \\
Difference & 0.823 & & & \\
After Referendum (wave 9) & 3.635 & & & \\
Remain voters & 2.784 & & & \\
Leave voters & -0.850 & 0.050 & 16.95 & $<.0005$ \\
Difference & -1.673 & 0.058 & 29.09 & $<.0005$ \\
\hline
\end{tabular}


Table A8 Differences-in-differences analysis of responses to fairness of the EU Referendum in wave 7 (before the EU referendum) and wave 10 (5 months after the EU referendum)

\begin{tabular}{cccccc}
\hline & $\begin{array}{c}\text { Estimated mean on } \\
\text { question about fairness } \\
\text { of how the EU } \\
\text { referendum is conducted } \\
\text { (1=fair; 5=unfair) }\end{array}$ & $\begin{array}{c}\text { standard } \\
\text { error }\end{array}$ & $|\mathrm{t}|$ & $\mathrm{p}$ \\
\hline Before Referendum (wave 7) & & & & \\
Remain voters & 2.858 & & & \\
Leave voters & 3.715 & 0.047 & 18.11 & $<.0005$ \\
Difference & 0.857 & & & \\
After Referendum (wave 10) & 4.017 & & & \\
Remain voters & 2.696 & & & \\
Leave voters & -1.322 & 0.051 & 26.17 & $<.0005$ \\
Difference & -2.179 & 0.062 & 35.32 & $<.0005$ \\
\hline
\end{tabular}

Table A9 Differences-in-differences analysis of responses to fairness of the EU Referendum in wave 7 (before the EU referendum) and wave 11 (10 months after the EU referendum)

\begin{tabular}{cccccc}
\hline & $\begin{array}{c}\text { Estimated mean on } \\
\text { question about fairness } \\
\text { of how the EU } \\
\text { referendum is conducted } \\
\text { (1=fair; 5=unfair) }\end{array}$ & $\begin{array}{c}\text { standard } \\
\text { error }\end{array}$ & $|\mathrm{t}|$ & $\mathrm{p}$ \\
\hline Before Referendum (wave 7) & 2.653 & & & \\
Remain voters & 3.513 & & & \\
Leave voters & 0.859 & 0.046 & 18.55 & $<.0005$ \\
Difference & & & & \\
After Referendum (wave 11) & 3.903 & & & \\
Remain voters & 2.402 & & & \\
Leave voters & -1.501 & 0.046 & 32.30 & $<.0005$ \\
Difference & -2.360 & 0.059 & 40.32 & $<.0005$ \\
\hline
\end{tabular}




\section{Details of the winner-loser effect on perceptions of fairness of the General Election of 2017}

Table A10 reports the effect on perceptions of the fairness of the General Election of winning (i.e. voting for the Conservative party) versus losing (voting for any of the other parties) in the 2017 General Election. Again, the substantive results remain the same when using different criteria for filtering cases (e.g., when only using respondents who took part in waves 11 and 13) and when using weights defined only for these two waves.

Table A10 Differences-in-differences analysis of responses to fairness of the General Election of 2017 in wave 11 (before 2017 General Election) and wave 13 (after 2017 General Election)

\begin{tabular}{|c|c|c|c|c|}
\hline & $\begin{array}{l}\text { Estimated mean on } \\
\text { question about fairness } \\
\text { of how the General } \\
\text { Election is conducted } \\
\text { (1=fair; } 5=\text { unfair) }\end{array}$ & $\begin{array}{c}\text { standard } \\
\text { error }\end{array}$ & $|\mathrm{t}|$ & $\mathrm{p}$ \\
\hline \multicolumn{5}{|l|}{ Before GE 2017 (wave 11) } \\
\hline Other voters & 3.336 & & & \\
\hline Conservative voters & 2.368 & & & \\
\hline Difference & -0.968 & 0.044 & -22.06 & $<.0005$ \\
\hline \multicolumn{5}{|l|}{ After GE2017 (wave 13) } \\
\hline Other voters & 3.102 & & & \\
\hline Conservative voters & 2.765 & & & \\
\hline Difference & -0.337 & 0.047 & 7.17 & $<.0005$ \\
\hline Difference-in-difference & 0.630 & 0.058 & 10.78 & $<.0005$ \\
\hline
\end{tabular}

Note: Winner-loser groups defined on vote in General Election (Conservative voters vs voters for all other parties); wave11 and wave13 data from BESIP; with covariates specified in text; clustered standard errors; only respondents who participated in all four waves (7, 9, 10, 11); weighted data (weighted $\mathrm{N}=6675-6789$ ) 


\section{Stata code for replication purposes}

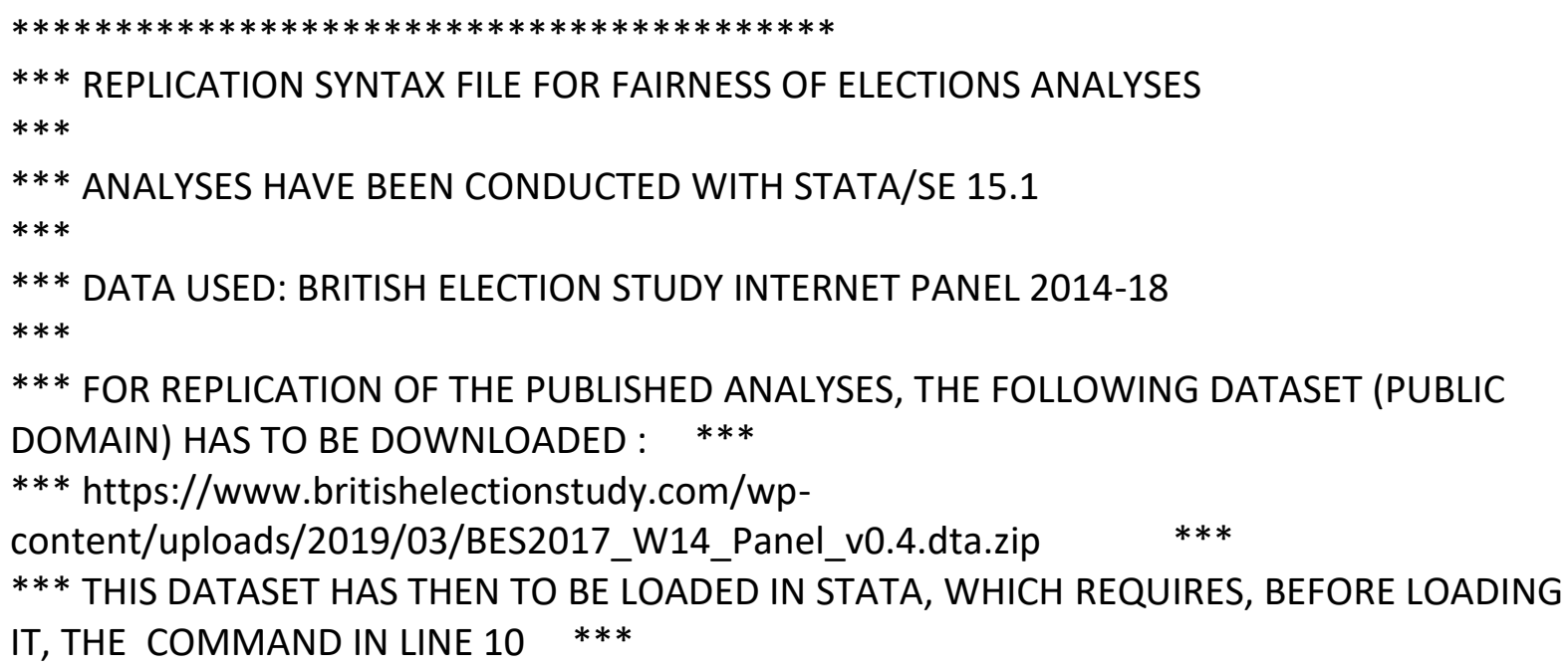

*** reduce number of variables by dropping those not used in the analyses $* * *$ keep id country wave 1 wave 2 wave 3 wave 4 wave 5 wave 6 wave7 wave 8 wave 9 wave10 wave11 wave12 wave13 wave14 country /// wt_new_W6_W11 wt_new_W6_W13 wt_new_W11_W13 generalElectionVoteW9 generalElectionVoteW13 /// satDemUK* expectGoodConductGeneral* euRefInterestW7 euRefInterestW8 euRefExpectationW7 euRefExpectationW8 /// polAttention* trustMPs* expectGoodConductEURef* goodConductEURef* happyLeaveW7 /// euRefVoteW9 electionInterestW11 /// ageGroup gender Age housing profile_socgradeW7 profile_work_statW7 profile_education_age profile_ethnicity /// profile_gross_household profile_gross_personal profile_eurefvote profile_newspaper *** define new variables required as covariates and define missing values where required $* * *$

generate Scotland $=$ country $==2$

generate Wales $=$ country $==3$

gen education_until_age = profile_education_age mvdecode education_until_age, mv (6 7) /* this recodes 'still at school / fulltime student into missing */ 
gen ethnic=profile_ethnicity

recode ethnic $1 / 2=13 / 15=216=9 / *$ this recodes into a dichotmoy: white vs non-white */ mvdecode ethnic, $\mathrm{mv}(9)$

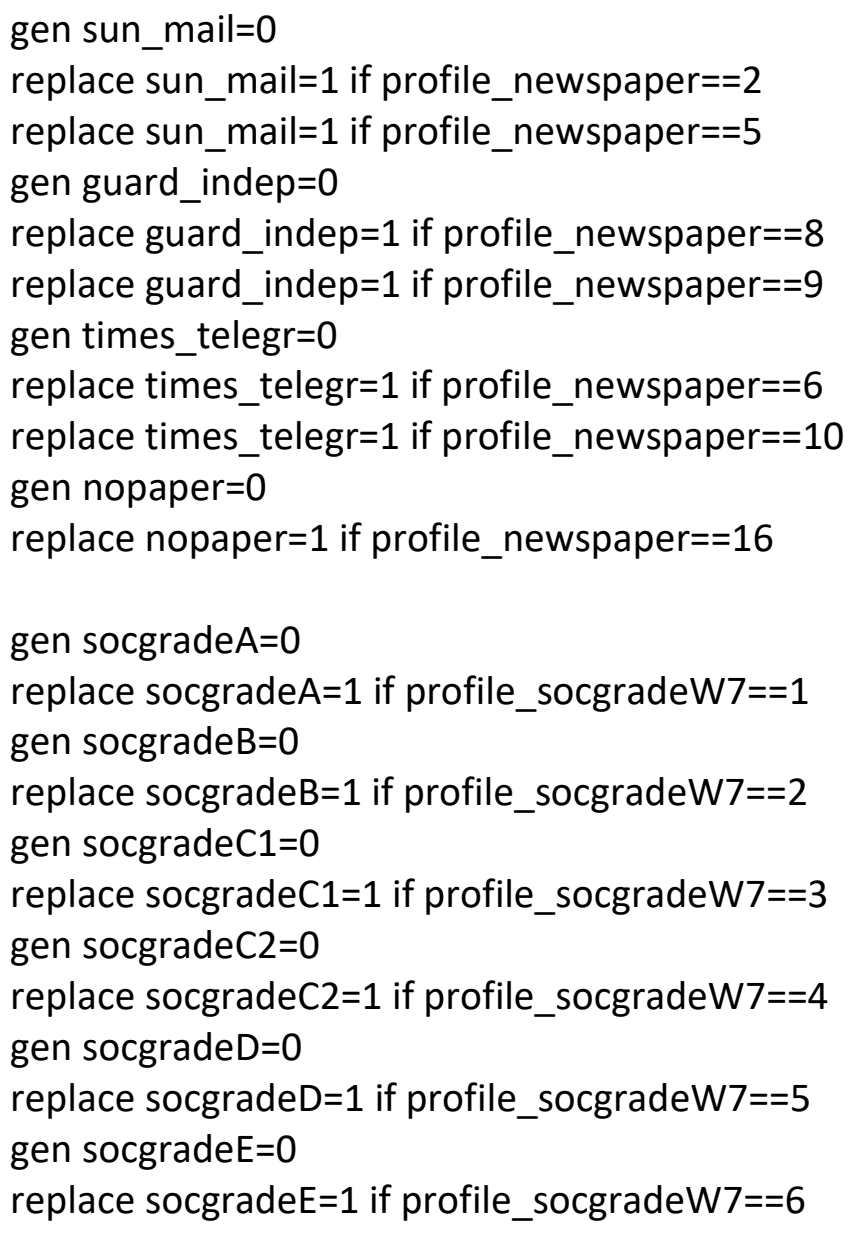

mvdecode expectGoodConductGeneralW2 expectGoodConductEURefW7 goodConductEURefW9 expectGoodConductEURefW10 ///

expectGoodConductEURefW11 expectGoodConductGeneralW11 expectGoodConductGeneralW13, mv(9999)

gen fairGE2=expectGoodConductGeneralW2 gen fairGE11=expectGoodConductGeneralW11

gen fairGE13=expectGoodConductGeneralW13

gen fairEU7=expectGoodConductEURefW7

gen fairEU9=goodConductEURefW9

gen fairEU10=expectGoodConductEURefW10

gen fairEU11=expectGoodConductEURefW11

gen wave1and 2 = wave $1+$ wave 2

gen wave79 = wave7 + wave9

gen wave791011 = wave7 + wave9 + wave10 + wave11

gen wave1113 = wave11 + wave13 
mvdecode polAttentionW1 trustMPsW1 satDemUKW1 polAttentionW2 trustMPsW2 satDemUKW2 polAttentionW3 trustMPsW3 ///

satDemUKW3 polAttentionW4 trustMPsW4 satDemUKW4 polAttentionW6 trustMPsW6 satDemUKW6 euRefInterestW7 ///

euRefExpectationW7 polAttentionW7 trustMPsW7 satDemUKW7 happyLeaveW7

euRefInterestW8 euRefExpectationW8 ///

polAttentionW8 satDemUKW8 trustMPsW8 trustMPsW9 satDemUKW9 polAttentionW10 trustMPsW10 satDemUKW10 ///

polAttentionW11 electionInterestW11 satDemUKW11 trustMPsW12 polAttentionW13 satDemUKW13 ///

polAttentionW14 euRefVoteW9, mv(9999)

*** make expectation variables W7 and W8 in 5 categories from $0-100$ scales; catergories defined as 0-39; 49-49; 50; 51-60; 61-100.

*** these to be used in check for $d-d-d$ effects that were already 'priced in' on basis of expectations.

gen expectW7=euRefExpectationW7

gen expectW8=euRefExpectationW8

recode expectW7 expectW8 $(0 / 39=0)(40 / 49=1)(50=2)(51 / 60=3)(61 / 100=4)$

tab1 expectW7 expectW8

*** replicate information in Table 1: Distribution of responses to referendum fairness

question

tab fairEU7 if wave791011==4 [iweight=wt_new_W6_W11], missing

tab fairEU9 if wave791011==4 [iweight=wt_new_W6_W11], missing

tab fairEU10 if wave791011==4 [iweight=wt_new_W6_W11], missing

tab fairEU11 if wave791011==4 [iweight=wt_new_W6_W11], missing

*** similar distributions (referred to in foornote 7) for General Election fairness questions tab fairGE2 if wave791011==4 [iweight=wt_new_W6_W11], missing

tab fairGE11 if wave791011==4 [iweight=wt_new_W6_W11], missing

tab fairGE13 if wave791011==4 [iweight=wt_new_W6_W11], missing

*** the same distributions but then for all respondents in respective waves and no weights tab fairGE2 if wave2==1, missing

tab fairGE11 if wave11==1, missing

tab fairGE13 if wave13==1, missing

$* * *$ if one wants to conduct further analyses on the 'wide' data structure, then one should save the file before

*** the restructure command (see lines 102-1-3 ), and save the reshaped data as a separate file

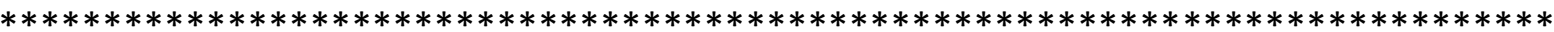

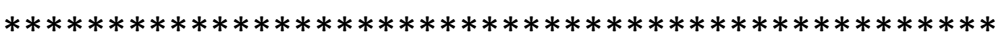


***reshaping data in long form; necessary for difference-in-differences analyses, which are conducted with diff routine

reshape long polAttentionW trustMPsW ///

satDemUKW fairGE fairEU, i(id) j(wave)

sort id wave

$* * *$ define variables that specify periods to be used in diff-in-diff analyses $* * *$

gen periodEU79=wave

recode periodEU79 $1 / 6=9$ 7=0 8=9 9=1 10/14=9

mvdecode periodEU79, $\mathrm{mv}(9)$

gen periodEU710=wave

recode periodEU710 1/6=9 7=0 8/9=9 10=1 11/14=9

mvdecode periodEU710, $\mathrm{mv}(9)$

gen periodEU711=wave

recode periodEU711 1/6=9 7=0 8/10=9 11=1 12/14=9

mvdecode periodEU711, $\mathrm{mv}(9)$

gen periodGE1113=wave

recode periodGE1113 $1 / 10=911=0$ 12=9 13=1 14=9

mvdecode periodGE1113, $\operatorname{mv}(9)$

gen periodEU12=wave $/ *$ this is for the placebo test reported in appendix $2 * /$

recode periodEU12 $1=02=13 / 14=9$

mvdecode periodEU12, $\mathrm{mv}(9)$

gen treatGE=generalElectionVoteW13

recode treatGE $1=12 / 9=0$

mvdecode treatGE, mv(9999)

*** define new variables to be used for subgroup analyses in Table 3

gen happyLeaveW7b=happyLeaveW7

recode happyLeaveW7b $7=16=25=3$

$* * *$ download and install external Stata module 'diff' with the following command

*** this requires that the computer on which one runs Stata has web-access

$* * *$

$* * *$ when the command in line 138 is executed

$* * *$

$* * * * * * * * * * * * *$

ssc install diff

*** replicate Table 2 
diff fairEU if wave791011==4 [pweight=wt_new_W6_W11] , period(periodEU79) treated(euRefVoteW9) ///

cov(Age gender Scotland Wales education_until_age ethnic socgradeA socgradeB socgradeC1 socgradeC2 socgradeD) ///

report cluster(id)

*** replicate Table 3

diff fairEU if wave791011==4 \& happyLeaveW7b==1 [pweight=wt_new_W6_W11] , period(periodEU79) treated(euRefVoteW9) ///

cov(Age gender Scotland Wales education_until_age ethnic socgradeA socgradeB socgradeC1 socgradeC2 socgradeD) ///

report cluster(id)

diff fairEU if wave791011==4 \& happyLeaveW7b==2 [pweight=wt_new_W6_W11] , period(periodEU79) treated(euRefVoteW9) ///

cov(Age gender Scotland Wales education_until_age ethnic socgradeA socgradeB socgradeC1 socgradeC2 socgradeD) ///

report cluster(id)

diff fairEU if wave791011==4 \& happyLeaveW7b==3 [pweight=wt_new_W6_W11] , period(periodEU79) treated(euRefVoteW9) ///

cov(Age gender Scotland Wales education_until_age ethnic socgradeA socgradeB socgradeC1 socgradeC2 socgradeD) ///

report cluster(id)

diff fairEU if wave791011==4 \& happyLeaveW7b==4 [pweight=wt_new_W6_W11] , period(periodEU79) treated(euRefVoteW9) ///

cov(Age gender Scotland Wales education_until_age ethnic socgradeA socgradeB socgradeC1 socgradeC2 socgradeD) ///

report cluster(id)

*** replicate Table 4

diff fairEU if wave791011==4 [pweight=wt_new_W6_W11] , period(periodEU79) treated(euRefVoteW9) ///

cov(Age gender Scotland Wales education_until_age ethnic socgradeA socgradeB socgradeC1 socgradeC2 socgradeD) ///

report cluster(id)

diff fairEU if wave791011==4 [pweight=wt_new_W6_W11], period(periodEU710) treated(euRefVoteW9) ///

cov(Age gender Scotland Wales education_until_age ethnic socgradeA socgradeB socgradeC1 socgradeC2 socgradeD) ///

report cluster(id) 
diff fairEU if wave791011==4 [pweight=wt_new_W6_W11], period(periodEU711) treated(euRefVoteW9) ///

cov(Age gender Scotland Wales education_until_age ethnic socgradeA socgradeB socgradeC1 socgradeC2 socgradeD) ///

report cluster(id)

*** replicate $\mathrm{d}-\mathrm{i}-\mathrm{d}$ analysis for General Election Fairness (reproted in text, just before footnote 7)

diff fairGE if wave791011==4 [pweight=wt_new_W6_W11], period(periodGE1113) treated(treatGE) ///

cov(Age gender Scotland Wales education_until_age ethnic socgradeA socgradeB socgradeC1 socgradeC2 socgradeD) ///

report cluster(id)

*** same replication by=ut then with w11-w13 weights and only for those participatin $g$ in w11 and w13

diff fairGE if wave1113==2 [pweight=wt_new_W11_W13], period(periodGE1113)

treated(treatGE) ///

cov(Age gender Scotland Wales education_until_age ethnic socgradeA socgradeB

socgradeC1 socgradeC2 socgradeD) ///

report cluster(id)

*** replicate placebo test on $\mathrm{w} 1$ and $\mathrm{w} 2$ with satisfaction with democracy as DV

diff satDemUKW if wave791011==4 [iweight=wt_new_W6_W11] , period(periodEU79) treated(euRefVoteW9) ///

cov(Age gender Scotland Wales education_until_age ethnic socgradeA socgradeB

socgradeC1 socgradeC2 socgradeD) ///

report cluster(id)

diff satDemUKW if wave791011==4 [iweight=wt_new_W6_W11] , period(periodEU12) treated(euRefVoteW9) ///

cov(Age gender Scotland Wales education_until_age ethnic socgradeA socgradeB

socgradeC1 socgradeC2 socgradeD) ///

report cluster(id)

diff satDemUKW if wave1and2==2 [iweight=wt_new_W6_W11] , period(periodEU12) treated(euRefVoteW9) ///

cov(Age gender Scotland Wales education_until_age ethnic socgradeA socgradeB socgradeC1 socgradeC2 socgradeD) ///

report cluster(id) 